\title{
Selective Medium for Isolation of Actinobacillus actinomycetemcomitans
}

\author{
JØRGEN SLOTS \\ Department of Oral Biology and Periodontal Disease Clinical Research Center, State University of New York \\ at Buffalo, Buffalo, New York 14226
}

Received 3 November 1981/Accepted 16 December 1981

\begin{abstract}
A selective medium, TSBV (tryptic soy-serum-bacitracin-vancomycin) agar, was developed for the isolation of Actinobacillus actinomycetemcomitans. TSBV agar contained (per liter) $40 \mathrm{~g}$ of tryptic soy agar, $1 \mathrm{~g}$ of yeast extract, $100 \mathrm{ml}$ of horse serum, $75 \mathrm{mg}$ of bacitracin, and $5 \mathrm{mg}$ of vancomycin. The TSBV medium suppressed most oral species and permitted significantly higher recovery of $A$. actinomycetemcomitans than nonselective blood agar medium. The distinct colonial morphology and positive catalase reaction of $A$. actinomycetemcomitans easily distinguished this bacterium from Haemophilus aphrophilus, Capnocytophaga species, and a few other contaminating organisms. With the TSBV medium, even modestly equipped laboratories will be able to isolate and identify A. actinomycetemcomitans from clinical specimens.
\end{abstract}

Isolation and identification of Actinobacillus actinomycetemcomitans has become increasingly important because of this organism's suspected role in certain types of human periodontal disease. Patients with localized juvenile periodontitis frequently harbor high numbers of $A$. actinomycetemcomitans in the subgingival plaque (6) and demonstrate high levels of serum antibodies against $\boldsymbol{A}$. actinomycetemcomitans (2; P. Hammond, J. Slots, and R. J. Genco, J. Dent. Res. 60A:498, 1981). Toxic substances from this organism including a potent endotoxin (4) and leukocidin $(1,7,8)$ may play a role in pathogenesis.

Development of a selective medium for the specific recovery of $A$. actinomycetemcomitans would be of particular value because the organism forms small, translucent colonies which will be readily overlooked if other organisms outnumber it significantly. Nevertheless, even if A. actinomycetemcomitans is present only in small proportions, it may be of etiological significance due to its virulence. Furthermore, the growth of $A$. actinomycetemcomitans can be inhibited in vitro by common oral streptococcal species (J. D. Hillman and S. S. Socransky, J. Dent. Res. 60A:603, 1981; Y. Yamamoto, P. A. Mashimo, H. Reynolds, and R. J. Genco, Abstr. Annu. Meet. Am. Soc. Microbiol. 1981, D41, p. 50). A bacterial medium which suppresses species that are inhibitory to A. actinomycetemcomitans should facilitate the recovery of the organism.

This paper describes and evaluates an improved medium for selective culturing of $A$. actinomycetemcomitans. This medium, which is designated TSBV, contains tryptic soy agar
(Difco Laboratories, Detroit, Mich.), $10 \%$ serum, and $0.1 \%$ yeast extract, and it includes the selective agents bacitracin $(75 \mu \mathrm{g} / \mathrm{ml})$ and vancomycin $(5 \mu \mathrm{g} / \mathrm{ml})$. A. actinomycetemcomitans, unlike most oral bacterial species, is highly resistant to bacitracin and vancomycin (J. Slots, Arch. Microbiol., in press).

\section{MATERIALS AND METHODS}

Bacterial strains. The $A$. actinomycetemcomitans strains used were: ATCC 29522, ATCC 29523, and ATCC 29524, obtained from the American Type Culture Collection, Rockville, Md.; NCTC 9709 and NCTC 9710, obtained from the National Collection of Type Cultures, London, England; Y4, obtained from S. S. Socransky, Boston, Mass.; and fresh clinical isolates $1,15,67,90,107$, and 125 , from our laboratory. The strains were maintained by weekly subculture on tryptic soy agar supplemented with $5 \%$ sheep blood and $0.1 \%$ yeast extract (BBL Microbiology Systems, Cockeysville, Md.) (TB medium) in an atmosphere of $90 \%$ air- $10 \% \mathrm{CO}_{2}$.

Medium. TSBV was prepared with tryptic soy agar to which was added $1.0 \mathrm{~g}$ of yeast extract per liter. The pH was adjusted to 7.2 , and the medium was autoclaved for $15 \mathrm{~min}$ at $121^{\circ} \mathrm{C}$. The medium was cooled to $50^{\circ} \mathrm{C}$, and horse serum and filter-sterilized bacitracin (Sigma Chemical Co., St. Louis, Mo.) and vancomycin (Sigma) were added to give final concentrations of $10 \%, 75 \mu \mathrm{g} / \mathrm{ml}$, and $5 \mu \mathrm{g} / \mathrm{ml}$, respectively. Preliminary studies with pure cultures of $A$. actinomycetemcomitans and dental plaque samples showed that these concentrations of serum, bacitracin, and vancomycin were optimal with respect to supporting growth of $A$. actinomycetemcomitans and suppressing growth of other oral species. The plates were stored aerobically at $5^{\circ} \mathrm{C}$ and used within 7 days of preparation.

Recovery efficiency of pure cultures of $\boldsymbol{A}$. actinomycetemcomitans. Test strains of $A$. actinomycetemcomi- 
TABLE 1. Comparative growth on nonselective TB medium and on TSBV medium of 12 pure cultures of $A$. actinomycetemcomitans

\begin{tabular}{llcr}
\hline Medium & \multicolumn{1}{c}{ Incubation } & $\begin{array}{c}\text { Geometric mean growth } \pm \\
\text { SD in \% of the TB } \\
\text { medium growth }\end{array}$ & $\begin{array}{c}\text { Median growth in \% } \\
\text { of the TB medium } \\
\text { growth }\end{array}$ \\
\hline TB & $85 \% \mathrm{~N}_{2}-10 \% \mathrm{H}_{2}-5 \% \mathrm{CO}_{2}$ & 100 & 100 \\
TSBV & $85 \% \mathrm{~N}_{2}-10 \% \mathrm{H}_{2}-5 \% \mathrm{CO}_{2}$ & $99 \pm 14$ & 103 \\
TSBV & $90 \%$ air-10\% CO & $96 \pm 43$ & 89 \\
TSBV & Candle jar & $85 \pm 23$ & 84 \\
\hline
\end{tabular}

tans were inoculated into prereduced, anaerobically sterilized brain heart infusion broth (BBL). Overnight cultures were dispersed by mixing with a Vortex mixer at the maximal setting for $60 \mathrm{~s}$ and were serially 10 -fold diluted in anaerobic Ringer solution. Using a bentglass rod, $0.1-\mathrm{ml}$ portions of $10^{-5}$ and $10^{-6}$ dilutions were spread on TB and TSBV plates. TB plates were incubated for $72 \mathrm{~h}$ at $37^{\circ} \mathrm{C}$ in a Coy anaerobic chamber (Coy Manufacturing Co., Ann Arbor, Mich.) containing $85 \% \quad \mathrm{~N}_{2}-10 \% \quad \mathrm{H}_{2}-5 \% \mathrm{CO}_{2}$. TSBV plates were incubated for $72 \mathrm{~h}$ at $37^{\circ} \mathrm{C}$ in a Coy anaerobic chamber, in a Torbal jar (The Torsion Balance Co., Clifton, N.J.) with no catalyst and containing $90 \%$ air- $10 \%$ $\mathrm{CO}_{2}$, and in a candle jar.

Clinical specimens. Subjects were adolescents who were admitted to our dental clinic for treatment of rapidly advancing periodontal disease on molars and incisors (localized juvenile periodontitis). Samples from deep periodontal pockets were obtained by using paper points as previously described (6). These were transferred to $9 \mathrm{ml}$ of anaerobic Ringer solution, the bacteria were dispersed by mixing with a Vortex mixer at the maximal setting for $60 \mathrm{~s}$, and the bacterial suspension was serially diluted in 10-fold steps in anaerobic Ringer solution. Using a bent-glass rod, 0.1$\mathrm{ml}$ portions of appropriate dilutions were plated on TB and TSBV. After incubation for $72 \mathrm{~h}$ at $37^{\circ} \mathrm{C}$ in a Coy anaerobic chamber, the plates were examined for $A$. actinomycetemcomitans. Randomly selected isolates suspected of being $A$. actinomycetemcomitans were subcultured and confirmed as A. actinomycetemcomitans if they were gram-negative, capnophilic (exhibited scant growth in air but grew well in $10 \% \mathrm{CO}_{2}$ ), fermentative, catalase-positive coccobacilli which did not require $\mathrm{X}$ (hemin) and $\mathrm{V}\left(\mathrm{NAD}^{+}\right)$factors for growth.

\section{RESULTS}

Table 1 shows the recovery efficacy of 12 strains of $A$. actinomycetemcomitans on TB after anaerobic chamber incubation and on TSBV after anaerobic chamber, Torbal jar with $90 \%$ air-10\% $\mathrm{CO}_{2}$, and candle jar incubation. For each strain tested, the viable count on TB in the anaerobic chamber (nonselective culturing) was designated $100 \%$, and the viable counts on the TSBV plates were compared with this. Under anaerobic incubation, growth on TSBV was similar to that on TB. Some inhibition tended to occur when incubation took place in $90 \%$ air$10 \% \mathrm{CO}_{2}$ or in a candle jar; however, the observed differences in recovery rates were not statistically significant at the $5 \%$ significance level as analyzed by the Wilcoxon signed-ranks test for matched pairs.

Fourteen specimens of advanced juvenile periodontitis lesions were obtained. Table 2 shows the number of $A_{\text {: }}$ actinomycetemcomitans re-

TABLE 2. Recovery of A. actinomycetemcomitans from dental plaque on TSBV medium and on TB medium after $72 \mathrm{~h}$ of anaerobic incubation

\begin{tabular}{|c|c|c|c|}
\hline \multirow[t]{2}{*}{ Specimen } & \multicolumn{2}{|c|}{$\begin{array}{l}\text { A. actinomycetemocomitans recovery } \\
\text { (colony-forming units) }\end{array}$} & \multirow{2}{*}{$\begin{array}{l}\% \text { Increase in } \\
\text { recovery on } \\
\text { TSBV medium }\end{array}$} \\
\hline & TSBV medium & $\overline{\text { TB medium }}$ & \\
\hline 1 & $144 \times 10^{2}$ & $88 \times 10^{2}$ & 64 \\
\hline 2 & $120 \times 10^{2}$ & $27 \times 10^{2}$ & 344 \\
\hline 3 & $450 \times 10^{3}$ & $42 \times 10^{3}$ & 971 \\
\hline 4 & $3 \times 10^{2}$ & $<10^{2}$ & \\
\hline 5 & $11 \times 10^{2}$ & $2 \times 10^{2}$ & 450 \\
\hline 6 & $528 \times 10^{2}$ & $106 \times 10^{2}$ & 398 \\
\hline 7 & $251 \times 10^{3}$ & $206 \times 10^{3}$ & 22 \\
\hline 8 & $180 \times 10^{3}$ & $19 \times 10^{3}$ & 847 \\
\hline 9 & $24 \times 10^{2}$ & $32 \times 10^{2}$ & -25 \\
\hline 10 & $294 \times 10^{3}$ & $140 \times 10^{3}$ & 110 \\
\hline 11 & $488 \times 10^{2}$ & $100 \times 10^{2}$ & 388 \\
\hline 12 & $772 \times 10^{2}$ & $152 \times 10^{2}$ & 408 \\
\hline 13 & $16 \times 10^{2}$ & $<10^{2}$ & \\
\hline 14 & $14 \times 10^{2}$ & $<10^{2}$ & \\
\hline
\end{tabular}

${ }^{a}$ Data were obtained by subtracting the value for TB medium from the value for TSBV medium, dividing the resulting number by the value for TB medium, and then multiplying by 100 . 


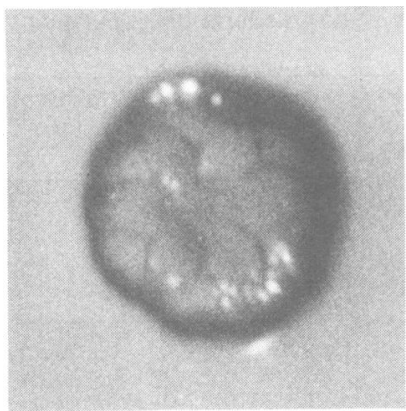

FIG. 1. Characteristic colony of A. actinomycetemcomitans after growth on TSBV for $72 \mathrm{~h}$. Note starlike inner structure. Photography performed with light transmitted through the medium.

covered on TB and TSBV media. Significantly, eight samples yielded 2- to 10-times higher counts of A. actinomycetemcomitans on TSBV than on TB. Also, in three samples in which $A$. actinomycetemcomitans occurred in low numbers, the organism could be recovered only on the TSBV medium.

Colonies of $A$. actinomycetemcomitans on TSBV appeared as circular, convex, translucent, glistening, and 0.5 to $1.0 \mathrm{~mm}$ in diameter with slightly irregular edges after incubation for 3 days. On primary isolation, the colonies strongly adhered to the agar surface and commonly exhibited a starlike inner structure (Fig. 1). Continued subculture resulted in loss of the adherence and the starlike structure.

Organisms other than A. actinomycetemcomitans which grew on TSBV in $90 \%$ air- $10 \% \mathrm{CO}_{2}$ or candle jar included mainly Haemophilus aphrophilus and Capnocytophaga species and occasionally Neisseria species, Staphylococcus-Micrococcus species, and yeasts. When incubated anaerobically, TSBV also supported growth of strains of fusobacteria and gram-negative anaerobic motile rods. The ability of $A$. actinomycetemcomitans to vigorously decompose $3 \% \mathrm{H}_{2} \mathrm{O}_{2}$ applied on the primary isolation plate could distinguish this organism from the morphologically similar catalase-negative or weakly catalase-positive $H$. aphrophilus. The remaining contaminants could readily be distinguished from A. actinomycetemcomitans on the basis of major differences in colonial morphology.

\section{DISCUSSION}

Most existing data on A actinomycetemcomitans in clinical infections have been obtained by using nonselective culture techniques. Since $A$. actinomycetemcomitans produces a small colony which readily can be overlooked and since various streptococcal species can inhibit the organism's growth in vitro, it seems appropriate to use a special selective procedure for the isolation of $A$. actinomycetemcomitans.

Kilian and Schiфtt (5) recovered A. actinomycetemcomitans from dental plaque by using chocolate agar supplemented with $300 \mu \mathrm{g}$ of bacitracin per $\mathrm{ml}$, a medium developed by Hovig and Aandahl (3) for the selective recovery of haemophili. The isolation and identification of A. actinomycetemcomitans on this medium can be hampered by the growth of streptococci, several Haemophilus species, Eikenella corrodens, and neisseriae (5).

Mandell and Socransky (R. L. Mandell and S. S. Socransky, J. Dent. Res. 59A:512, 1980) isolated A. actinomycetemcomitans on Trypticase soy agar (BBL Microbiology Systems) supplemented with $128 \mu \mathrm{g}$ of bacitracin per $\mathrm{ml}, 8 \mu \mathrm{g}$ of malachite green per $\mathrm{ml}$, and $5 \%$ sheep blood. This medium suppressed the growth of pure cultures of $A$. actinomycetemcomitans as much as $20 \%$. The malachite green, which at relatively low concentrations can be inhibitory to $A$. actinomycetemcomitans (Slots, in press), may be responsible for this suppression. Mandell and Socransky's medium also may grow several contaminating Haemophilus species because of the blood supplement.

The TSBV medium overcomes several of these problems. The enrichment with $10 \%$ horse serum instead of with blood did not change the recovery rate of $A$. actinomycetemcomitans, but it suppressed hemin-requiring Haemophilus strains and allowed direct application of $\mathrm{H}_{2} \mathrm{O}_{2}$ to the primary isolation plate to verify the $A$. actinomycetemcomitans diagnosis. Bacitracin was added because many oral species are particularly susceptible to this antibiotic (Slots, unpublished data). The vancomycin content of 5 $\mu \mathrm{g} / \mathrm{ml}$ suppressed the growth of potentially inhibitory streptococcal strains and other grampositive species. Our finding of lower recovery rates of A. actinomycetemcomitans from clinical specimens on nonselective blood agar medium than on TSBV suggests that in vitro bacterial antagonism against $A$. actinomycetemcomitans can be of a significant magnitude. Additional suppression of contaminants could be achieved by incubating in $90 \%$ air $-10 \% \mathrm{CO}_{2}$ or in a candle jar instead of anaerobically. The observation that the candle jar system provided good growth for A. actinomycetemcomitans may be of value in a clinical setting or in epidemiological studies where microbiological facilities are limited.

In conclusion, the TSBV medium described in this report can considerably aid the microbiological monitoring of $A$. actinomycetemcomitans; it is relevant in the diagnosis and treatment of $\boldsymbol{A}$. actinomycetemcomitans infections. 


\section{ACKNOWLEDGMENTS}

This investigation was supported in part by Public Health Grant DE04898 from the National Institute of Dental Research. The assistance of H. S. Reynolds is highly appreciated.

\section{LITERATURE CITED}

1. Baehni, P., C.-C. Tsai, W. P. McArthur, B. F. Hammond, and N. S. Taichman. 1979. Interaction of inflammatory cells and oral microorganisms. VIII. Detection of leukotoxic activity of a plaque-derived gram-negative microorganism. Infect. Immun. 24:233-243.

2. Genco, R. J., J. Slots, C. Mouton, and P. Murray. 1980. Systemic immune responses to oral anaerobic organisms, p. 277-293. In D. W. Lambe, Jr., R. J. Genco, and K. J. Mayberry-Carson (ed.), Anaerobic bacteria: selected topics. Plenum Press, New York and London.

3. Hovig, B., and E. H. Aandahl. 1969. A selective method for the isolation of Haemophilus in material from the respiratory tract. Acta Pathol. Microbiol. Scand. 77:676684.
4. Kiley, P., and S. C. Holt. 1980. Characterization of the lipopolysaccharide from Actinobacillus actinomycetemcomitans Y4 and N27. Infect. Immun. 30:862-873.

5. Kilian, M., and C. R. Schiott. 1975. Haemophili and related bacteria in the human oral cavity. Arch. Oral Biol. 20:791-796.

6. Slots, J., H. S. Reynolds, and R. J. Genco. 1980. Actinobacillus actinomycetemcomitans in human periodontal disease: a cross-sectional microbiological investigation. Infect. Immun. 29:1013-1020.

7. Taichman, N. S., R. T. Dean, and C. J. Sanderson. 1980 Biochemical and morphological characterization of the killing of human monocytes by a leukotoxin derived from Actinobacillus actinomycetemcomitans. Infect. Immun. 28:258-268.

8. Tsai, C.-C., W. P. McArthur, P. C. Baehni, B. F. Hammond, and N. S. Taichman. 1979. Extraction and partial characterization of a leukotoxin from a plaque-derived gram-negative microorganism. Infect. Immun. 25:427439. 